\title{
Detecting changes on coastal primary sand dunes using multi-temporal Landsat Imagery
}

\author{
Gil Gonçalves ${ }^{\text {ab }}$, Nuno Duro ${ }^{\mathrm{c}}$, Ercília Sousa ${ }^{\mathrm{bd}}$, Luís Pinto ${ }^{\mathrm{bd}}$, Isabel Figueiredo ${ }^{\text {bd }}$

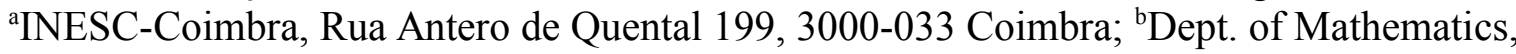 \\ University of Coimbra; ${ }^{\mathrm{C}}$ www.bluecover.pt; ${ }^{\mathrm{d}} \mathrm{CMUC}$, Apartado 3008, EC Santa Cruz, 3001 - 501 \\ Coimbra
}

\begin{abstract}
Due to both natural and anthropogenic causes the coastal primary sand dunes, keeps changing dynamically and continuously their shape, position and extend over time. In this paper we use a case study to show how we monitor the Portuguese coast, between the period 2000 to 2014, using free available multi-temporal Landsat imagery (ETM+ and OLI sensors). First, all the multispectral images are panshaperned to meet the 15 meters spatial resolution of the panchromatic images. Second, using the Modification of Normalized Difference Water Index (MNDWI) and kmeans clustering method we extract the raster shoreline for each image acquisition time. Third, each raster shoreline is smoothed and vectorized using a penalized least square method. Fourth, using an image composed by five synthetic bands and an unsupervised classification method we extract the primary sand dunes. Finally, the visual comparison of the thematic primary sand dunes maps shows that an effective monitoring system can be implemented easily using free available remote sensing imagery data and open source software (QGIS and Orfeo toolbox).
\end{abstract}

Keywords: Coastal change detection, Landsat imagery, unsupervised classification, Open source software.

\section{INTRODUCTION}

Primary sand dunes (or fore-dunes for short) are often the nearest seaward feature of coastal aeolian systems and represent the nearest landward part of the sand-sharing system associate with beach dune interaction [1]. Due to both natural and anthropogenic causes the coastal primary sand dunes, these mounds of unconsolidated sandy soil which are continuous to the shoreline, keeps changing dynamically and continuously their shape, position and extend over time. Detection, extraction and monitoring these areas using remote sensing techniques and technologies are important issues for countries like Portugal where 85\% of its GDP (Gross Domestic Product) is generated in the coastal zone and in which lives more than $75 \%$ of its population. Moreover, delineate automated procedures for detecting changes in the primary sand dunes using free available data sources and software is also an important issue nowadays.

To monitor the coastal zones it is necessary to use the knowledge from a large number of disciplines [2]. In this paper we use a Remote Sensing perspective to show how we monitor the Portuguese coast, between the period 2000 to 2014, using free available multi-temporal Landsat imagery (ETM+ and OLI sensors). First, in order to monitor the shoreline for the period under analysis the ETM+ multispectral images and the OLI images are panshaperned to meet the spatial resolution of the panchromatic bands $(15 \mathrm{~m})$. This is an essential step as we will increase the spatial resolution while we will maintain the spectral quality of the Landsat imagery. Second, for monitoring the primary sand dunes an unsupervised classification (kmeans) is used together with a visual analysis to track the changes in the land cover classes obtained for each classified image.

\section{STUDY AREA AND IMAGE DATA}

The study area is a sandy beach stretch of $75 \mathrm{~km}$ located in the Portuguese north-west coast and is one of the most dynamic areas of the Portuguese west littoral [3]. This coastline stretch is characterised morphologically by a sandy shore, exposed directly to highly energetic waves, and by primary sand dunes (frontal dunes) with its baseline forming a

* gil@mat.uc.pt; phone: +351239791150 
relatively straight alignment. For the last years this stretch has been subjected to critical erosion and some of the primary sand dunes suffered an erosion rate of $10 \mathrm{~m} / \mathrm{y}[3]$.

The Landsat imagery was downloaded from the US Geological Survey web site (http://glovis.usgs.gov/). For downloading some important criteria have been defined for image selection: i) if possible all the images have been acquired more or less at the same time of the year; ii) only the images with the best radiometric and atmospheric (free coastline cloud cover) have been selected. However, for evaluate the tidal effect on the extracted shoreline an additional corresponding to a low tidal event (see section 3.2 and section 4.1) have been selected for the year of 2014. Table 1 shows the specifications of satellite data used in this study. The estimated tidal height is interpolated using the equations given in section 3.2 .

Table 1. Image date and tidal conditions during image acquisition.

\begin{tabular}{|c|c|c|c|c|c|c|c|}
\hline \multicolumn{5}{|c|}{ Images } & \multicolumn{3}{c|}{ Tide } \\
\hline Row-Path & Date & Sensor & $\begin{array}{c}\text { Image } \\
\text { name }\end{array}$ & $\begin{array}{c}\text { Acq. } \\
\text { GMT }\end{array}$ & $\begin{array}{c}\text { Max } \\
\text { GMT }-\mathrm{h}(\mathrm{m})\end{array}$ & $\begin{array}{c}\text { Min } \\
\text { GMT }-\mathrm{h}(\mathrm{m})\end{array}$ & $\begin{array}{c}\text { Estim. } \\
\mathrm{h}(\mathrm{m})\end{array}$ \\
\hline \multirow{5}{*}{$204-032$} & $2000-06-24$ & ETM+ & 2000 & $11: 06$ & $07: 42-2.62$ & $13: 40-1.26$ & 1.8 \\
\cline { 2 - 9 } & $2002-06-30$ & ETM+ & 2002 & $11: 02$ & $06: 26-2.71$ & $12: 19-1.12$ & 1.3 \\
\cline { 2 - 9 } & $2013-06-20$ & OLI & 2013 & $11: 16$ & $12: 01-3.11$ & $05: 41-0.94$ & 3.0 \\
\cline { 2 - 9 } & $2014-03-19$ & OLI & $2014 \mathrm{a}$ & $11: 14$ & $16: 43-3.38$ & $10: 16-0.6$ & 0.8 \\
\cline { 2 - 9 } & $2014-07-09$ & OLI & $2014 \mathrm{~b}$ & $11: 13$ & $12: 10-3.05$ & $05: 50-1.04$ & 2.9 \\
\hline
\end{tabular}

Figure 1 shows the four images used in this study to detect the changes on primary sand dunes and to extract the instantaneous shoreline. The 2014a image is not shown in this figure since it is only used with the purpose of illustrate the tidal height effect on the position of the shoreline.

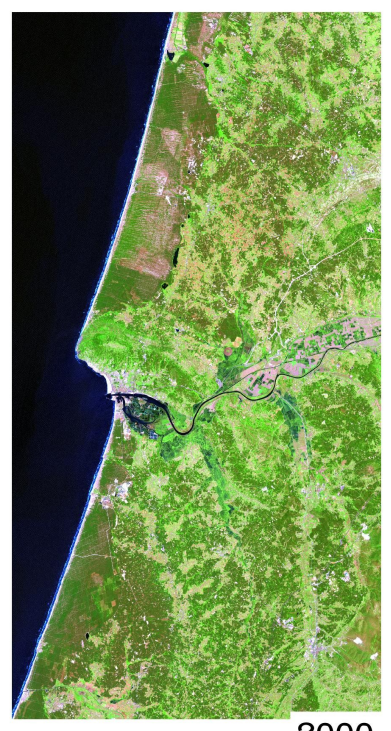

2000

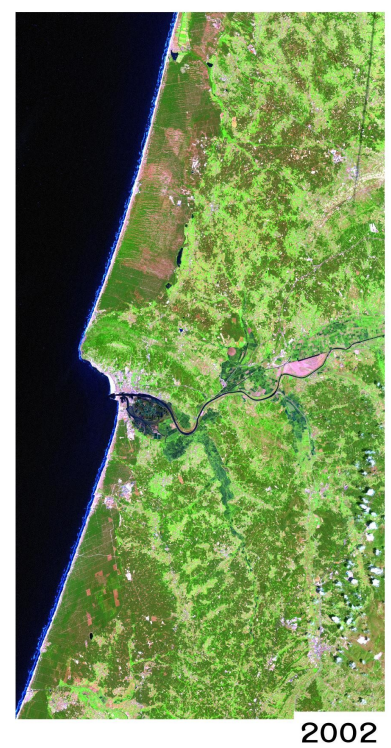

2002

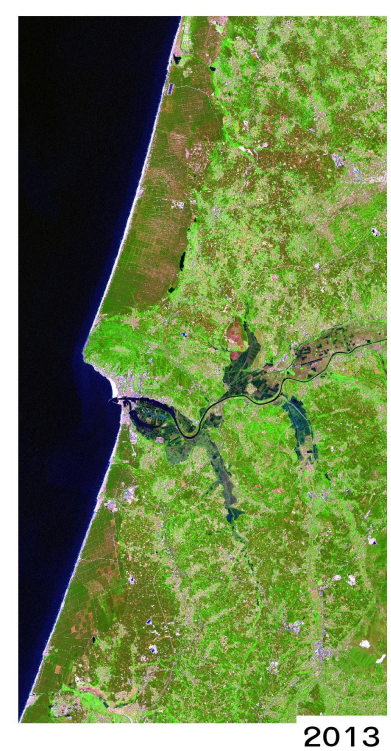

2013

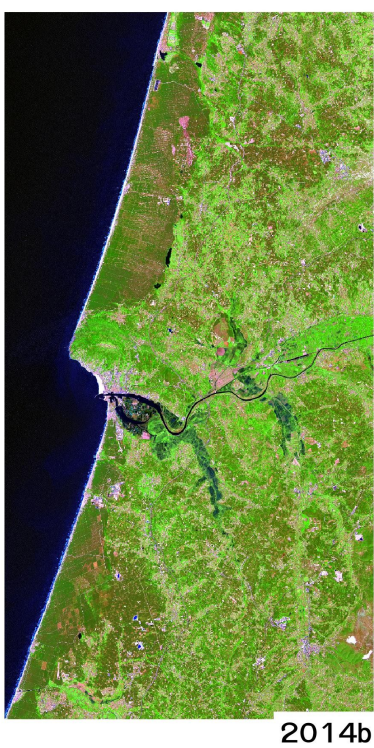

2014b

Figure 1. Landsat images used in this study. The images are displayed as false colour composition (RGB=SWIR1,NIR,G). 


\section{METHODOLOGY}

The overall methodology is shown Figure 2. Basically it is composed by two separate stages. In the first stage we extract the shoreline. In the second stage we use an image composed by five derived bands: the first three bands are the NDVI, MNDWI and NDBI indexes and the other two are the two first principal components (PC1, PC2) computed from the six extracted Landsat ETM+ and OLI bands. Temporal changes have been detected by examining the results of image classification for the bare sand class.

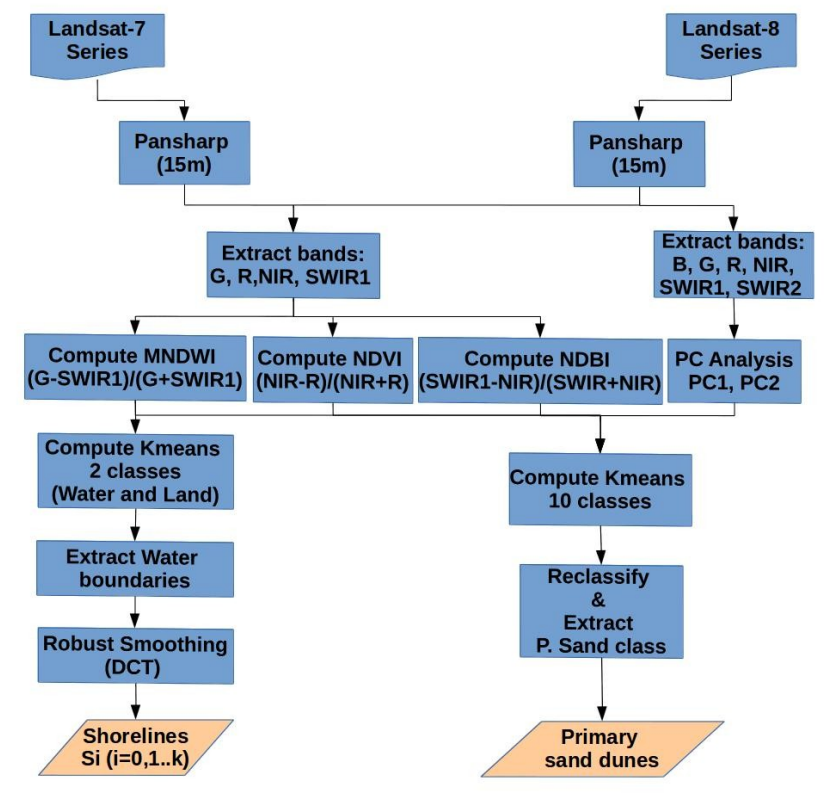

Figure 2. Flowchart describing the overall methodology.

\subsection{Shoreline extraction and smoothing}

The extraction of water information from multispectral satellite images can be done by analysing the signatures of each ground target among the different spectral bands and using these signatures as input for a specific classification method. Another way is using a band ratio approach of two spectral bands. Ratio images are calculated by dividing for each pixel the DN values in one spectral band by the corresponding pixel value in another band. The advantages of using the band ratio approaches compared to the other approaches is that the environmental induced variations in the DN values of a single spectral band are reduced by considering the ratio between two bands ([4], [5]). In this paper we use the Modified Normalized Difference Water Index $(M N D W I)$ as it can efficiently suppress from the water information the noise coming from built-up land, vegetation and soil [6]

$$
M N D W I=\frac{\text { Green }- \text { SWIR1 }}{\text { Green }+ \text { SWIR1 }}
$$

For shoreline extraction we use a single image formed by the MNDWI and the kmeans method to separate water from land (see Figure 2).

To smooth the extracted raster shoreline we use the robust and fully automated smoothing procedure proposed by [7]. This procedure involves the use of a discrete cosine transform to solve the following linear system that allows the determination of the smoothed data $(\hat{y})$ :

$$
\left(I_{n}+s D^{\top} D\right) \hat{y}=y
$$

where $y$ is the the raster shoreline (vectorial line defined by the centres of the $n$ extracted shoreline pixels), $s$ is the smoothing parameter, $D$ is a triagonal square matrix expressing the 2 nd order divided differences, and $I_{n}$ is the $n \times n$ 
identity matrix. Using the fact that the data are equally spaced (note that we are dealing with a raster line) the equation (2) can be rewritten as ([4]):

$$
\hat{y}=\operatorname{ICDT}(\Gamma \cdot \operatorname{CDT}(y))
$$

where $\Gamma$ is a diagonal matrix whose elements are given by $\Gamma_{i, i}=\left[1+s(2-2 \cos ((i-1) \pi / n))^{2}\right]^{-1}$, CDT and ICDT are the discrete cosine transform and the inverse discrete cosine transform, respectively. Although the smoothing parameter $s$ can be automatically estimated by the method of generalized cross-validation (GCV) we prefer to set it manually to a fixed value in order to keep it constant for all experiments. This value ( $\mathrm{s}=3$ ) have been determined by trial-and-error and using one of the extracted raster shoreline (see figure 3).

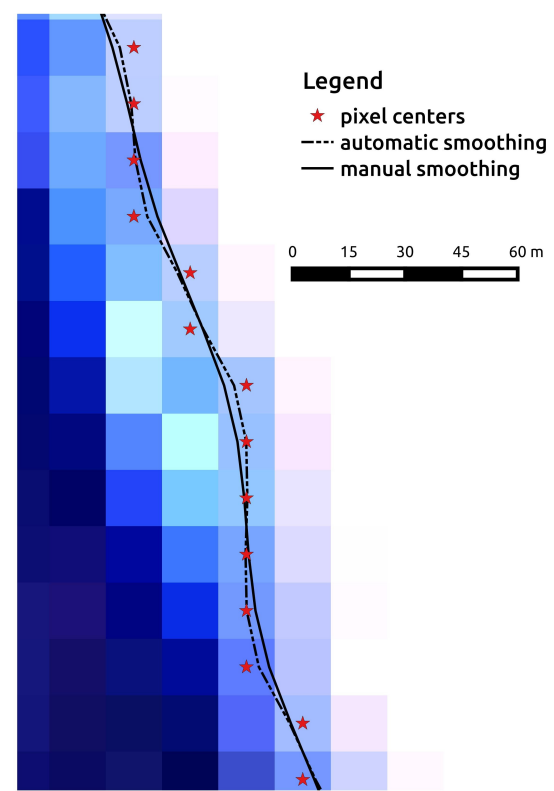

Figure 3. Smoothing the extracted raster shoreline.

\subsection{Tidal height effect on the position of the shoreline}

Because the accuracy of the shoreline position extracted from satellite images depends on the range of tidal height at the satellite overpass time [8], it is important to estimate the tidal height $(y)$ at the time of image acquisition $(t)$. Denoting by $h_{\max }$ the height of the high tide, $h_{\min }$ the height of low tide, $\Delta T$ the time interval between the low and the high tide, and $\Delta t$ the time interval between the preceding event (high or low tide) and the time of image acquisition the tidal height can be estimated using the equation [9]

$$
y=\frac{h_{\max }+h_{\min }}{2} \pm \frac{h_{\max }-h_{\min }}{2} \cos \frac{\pi \Delta t}{\Delta T}
$$

where the minus symbol should be used in case the preceding event is a low tide.

Table 1 shows the estimated tidal heights for the five Landsat images at the time of image acquisition. It is worth to note that for the five images used in this study the tidal range can reach up to $2.2 \mathrm{~m}$. In order to analyse the effect of tidal height on the position of the extracted shoreline we will use two images (2014a and 1024b) for mapping the area between the low and the high tide [10]. In this way we can identify the areas where the detected changes of the shoreline position must be neglected because of the tidal height effect.

\subsection{Primary sand dunes extraction}

In order to extract the primary sand dunes, the first step is to build an image composed by five synthetic (artificial) bands. The first band is a ratio image corresponding to the $M N D W I$ and its purpose is to enhance the water features. The second band is also a ratio image corresponding to the Normalized Difference Vegetation Index (NDVI), and is given by 


$$
N D V I=\frac{N I R-R e d}{N I R+R e d}
$$

The purpose of this band is to enhance the vegetation targets that may exist on some primary sand dunes. The third band is a ratio image corresponding to the Normalized Difference Built Up Index (NDBI), as proposed by [11], and is used in order to separate the built-up areas from the other areas:

$$
N D B I=\frac{S W I R 1-N I R}{S W I R 1+N I R}
$$

The last fourth and fifth bands are, respectively, the first two principal component images obtained from the five $15 \mathrm{~m}$ pansharpened ETM+ and Oli image bands: Green, Red, Blue, NIR, SWIR1, SWIR2.

Finally, the second step consists in using the kmeans, a non-supervised clustering algorithm, in order to obtain the cluster(s) that will represent the primary sand dunes class. In order to assess the change detection in the primary sand dunes it is necessary to reclassify the classified images to the same land cover nomenclature. For this task we have used the on-line Web Map Service (WMS) for Remote Sensing Imagery as provided by Google Satellite and Bing Aerial. Using the online imagery we identify the stable clusters in the four classified images take into consideration the date of the images provided by the WMS. In the future we hope to replace the WMS image data with $0.5 \mathrm{~m}$ ortophotos provided by the Portuguese Ortophoto Programme for the 2012 year. Using these image data we also intend to perform an assessment of the thematic classification accuracy for the two most recent classified images (2013 and 2014).

\section{RESULTS}

\subsection{Shoreline extraction}

Figure 4 shows the extracted shorelines for the period under analysis. Neglecting the tide height effect on the extracted shorelines Area 1 shows and evident erosion and Area 2 an evident accretion.
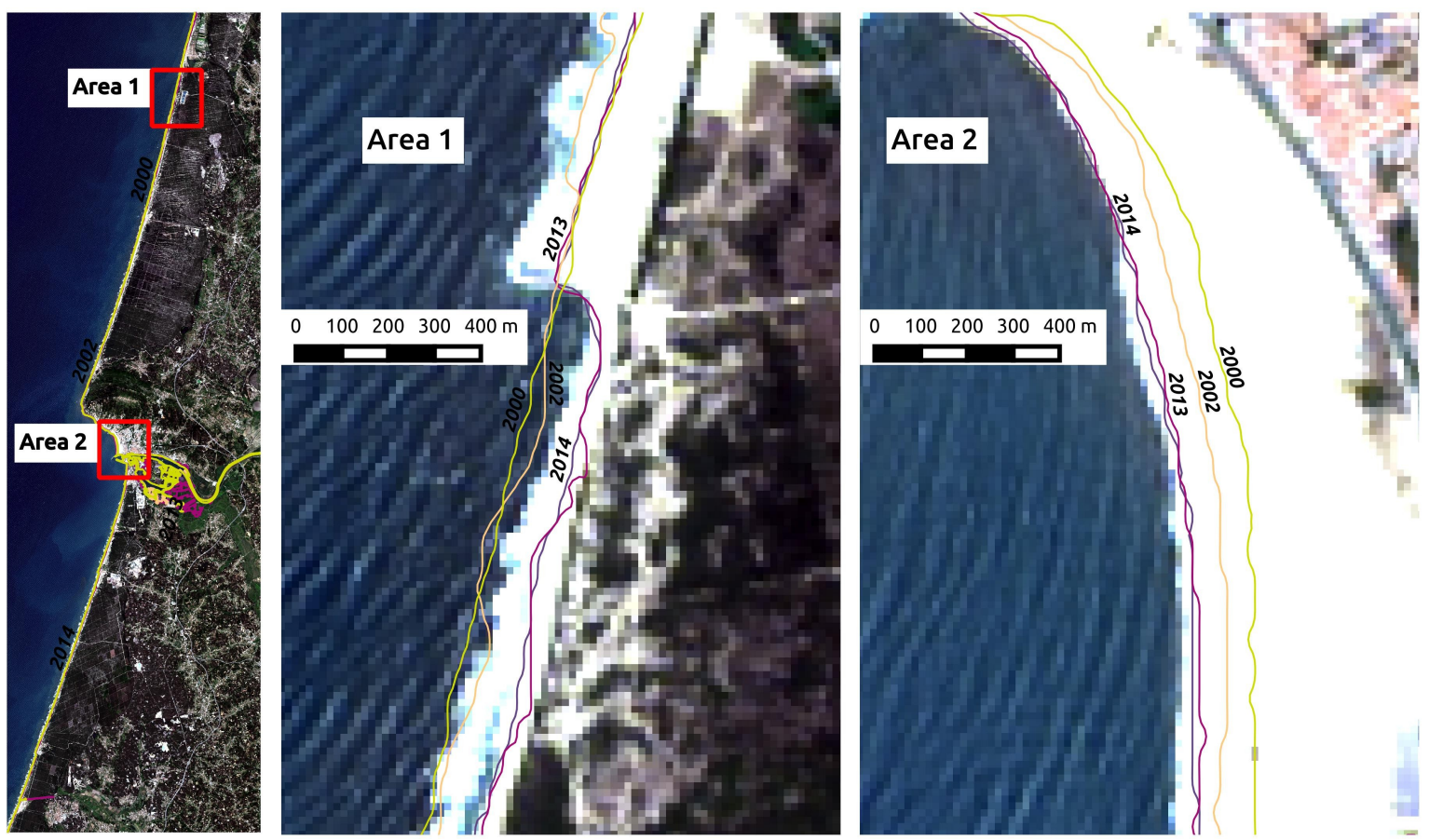

Figure 4. Extracted shorelines for years 2000, 2002, 2013, and 2014. Area 1 shows an erosion, Area 2 shows and accretion. 


\subsection{Tidal height effect}

Figure 5 shows the effect of tidal height on the extracted shoreline for the two images corresponding to the year 2014. It is clear that in the accretion area (Area 2) the tidal height effect can be neglected as the two instantaneous shorelines are very close. However, in the erosion area (Area 1) the two instantaneous shorelines corresponding to the low and high tides are well separated which means that the slope is less steep than in the previous area. Therefore, although there is an evident erosion in this area, further research is needed before this phenomenon can be adequately explained.

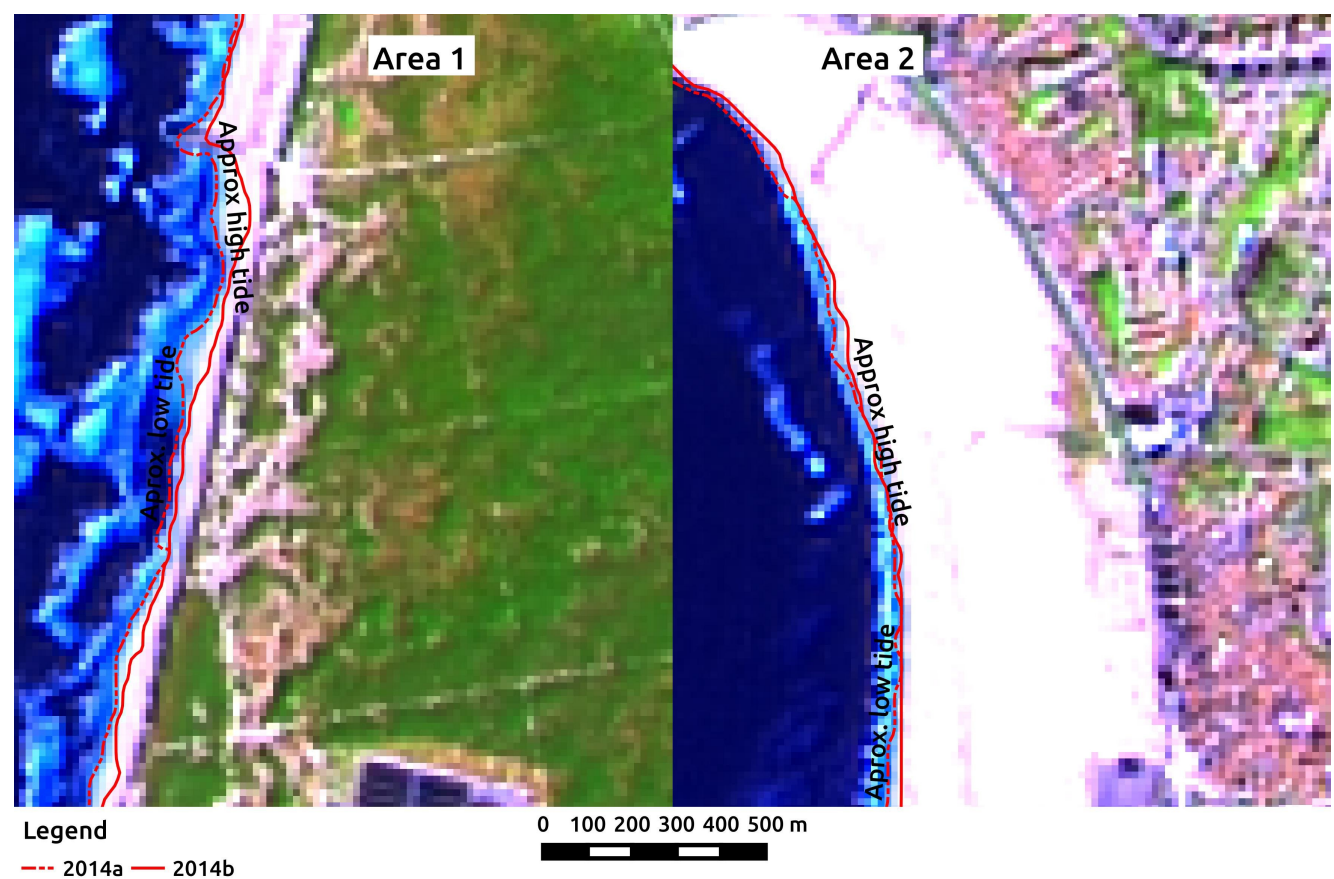

Figure 5. The effect of tide height on the position of the extracted shorelines.

\subsection{Primary sand dunes extraction}

Figure 6 shows some of the results obtained for the extraction of the primary sand dunes. In the upper part we show the four composite images used in the unsupervised kmeans classification corresponding to the four years (2000, 2002, 2013, and 2014). The kmeans was performed using the the default parameters except the training set size that was set to 1000 and, of course, the number of classes that was set to 10. In the lower part we show the corresponding classified images. From the 10 identified clusters 7 thematic classes were depicted: Water; Primary sand dunes (PSandDunes - sand dunes with some dry vegetation); bare sand (Sand); bare soil 1 (BareSoil1); bare soil 2 (BareSoil2); vegetation 1 (Veg1); vegetation 2 (Veg2). Finally, considering only the classification results for PSandDunes a visual and qualitative analysis was been done, which clearly revealed that the primary sand dunes class have suffered considerable erosion since 2000.

\section{CONCLUSIONS}

In this work we shown that an effective monitoring system can be implemented easily using free available remote sensing imagery data and open source software (QGIS and Orfeo toolbox).

Future development of this methodology will focus on: i) implementing a tide-coordinate shoreline extraction procedure by making use of two images per year corresponding to a hide tide and a low tide, and ii) implementing an automatic assessment procedure for monitoring the changes on the primary sand dunes, by examining the changes on the bare sand class and on the first line vegetation class.

\section{ACKNOWLEDGMENTS}


This work was partially supported by the Foundation for Science and Technology (FCT) of Portugal in the framework of the project PTDC/MAT-NAN/0593/2012 through European program COMPETE/FEDER and project PEst-OE/ $\mathrm{EEI} / \mathrm{UI} 308 / 2014$.

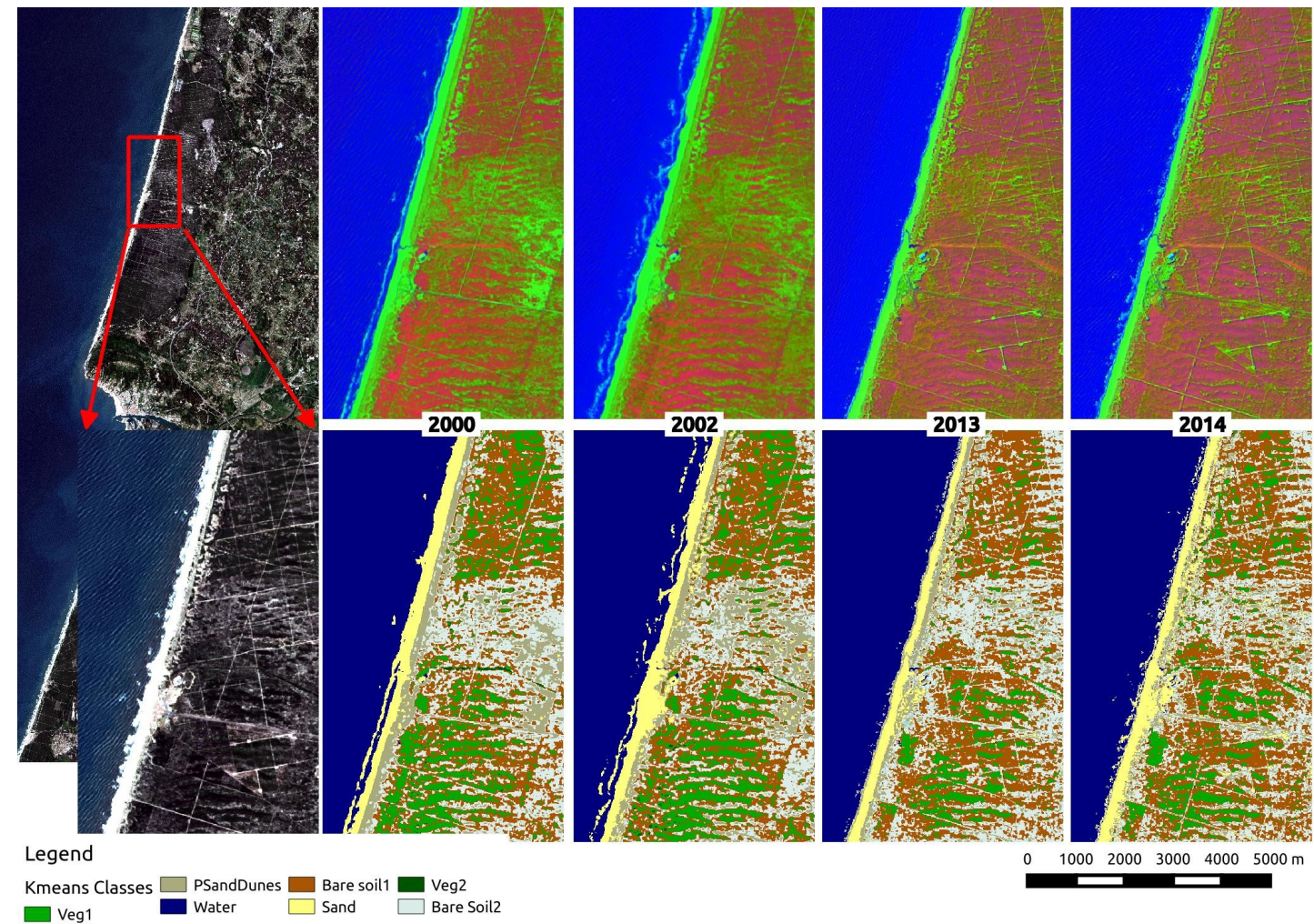

Figure 6. Extraction of primary sand dunes (PsandDunes) from the 4 generated synthetic images (4 upper images) using kmeans classification (4 lower images).

\section{REFERENCES}

[1] Ryu, W. and Sherman, D. J. "Foredune Texture: Landscape Metrics and Climate", Annals of the Association of American Geographers 104(5), 903-921 (2014).

[2] Gens, R. "Remote sensing of coastlines: detection, extraction and monitoring", International Journal of Remote Sensing 31(7), 1819-1836 (2010).

[3] Baptista, P.; Cunha, T.; Bernardes, C.; C. Gama; Ferreira, O. and Dias, A. "A Precise and Efficient Methodology to Analyse the Shoreline Displacement Rate", Journal of Coastal Research 27(2), 223-232 (2011).

[4] Song, C.; Woodcock, C. E.; Seto, K. C.; Lenney, M. P. and Macomber, S. A. "Classification and Change Detection Using Landsat TM Data: When and How to Correct Atmospheric Effects?", Remote Sensing of Environment 75(2), 230$244(2001)$

[5] Tran, T. V. and Trinh, T. B. "Application of remote sensing for shoreline change detection in Cuu Long estuary", VNU Journal of Science, Earth Sciences 25(4), 217-222 (2009).

[6] Xu, H. "Modification of normalised difference water index (NDWI) to enhance open water features in remotely sensed imagery", International Journal of Remote Sensing 27(14), 3025-3033 (2006).

[7] Garcia, D. "Robust smoothing of gridded data in one and higher dimensions with missing values", Computational Statistics \& Data Analysis 54(4), 1167 - 1178 (2010).

[8] Yu, K.; Hu, C.; Muller-Karger, F. E.; Lu, D. and Soto, I. "Shoreline changes in west-central Florida between 1987 and 2008 from Landsat observations", International Journal of Remote Sensing 32(23), 8299-8313 (2011).

[9] Hidrográfico, I. "Tabelas de Maré (in portuguese)", Instituto Hidrográfico, (2014). 
[10] Murray, N. J.; Phinn, S. R.; Clemens, R. S.; Roelfsema, C. M. and Fuller, R. A. "Continental Scale Mapping of Tidal Flats across East Asia Using the Landsat Archive", Remote Sensing 4(11), 3417-3426 (2012).

[11] Zha, Y.; Gao, J. and Ni, S. "Use of normalized difference built-up index in automatically mapping urban areas from TM imagery", International Journal of Remote Sensing 24(3), 583-594 (2003). 